\title{
PENANGANAN HASIL TANGKAPAN IKAN TUNA PADA COLD STORAGE DENGAN SISTEM AIR BLAST DI PT AWINDO INTERNATIONAL PELABUHAN PERIKANAN SAMUDERA NIZAM ZACHMAN JAKARTA
}

\author{
Fazhur R. Launuru' ${ }^{1)}$, Urip Rahmani ${ }^{2)}$ \\ ${ }^{1,2,3)}$ Jurusan Pemanfaatan Sumberdaya Perikanan, FPIK USNI \\ Jln, Arteri Pondok Indah No. 11 Jakarta 12240 \\ E-mail: rakib_launuru06@yahoo.com
}

\begin{abstract}
PT Awindo International is one of the companies engaged in the processing of fishery products, Including one of tuna loin products. The company is located within the Ocean Fishing Port area of Nizam Zachman Jakarta. The company is committed to the production and marketing as well as to the safety of fishery products in meeting International and Indonesia requirements on Hazard Analysic Critical Control Point (HACCP) quality systems or food safety management. In accordance with the Minister of Transportation Decree No. KM.35 / AL.003 / PHB-82 PPSNZJ is precisely located at coordinates: $106^{\circ} 48^{\prime} 15^{\prime \prime E a s t ~ a n d ~} 06^{\circ} 06^{\prime} 18^{\circ} \mathrm{LS} ; 106^{\circ} 47^{\prime} 54^{\prime}$ "East and $06^{\circ}$ 06 '20 "LS; $106^{\circ} 48^{\prime} 14$ "BT and $06^{\circ} 05^{\prime} 32^{\prime \prime} \mathrm{LS} ; 106^{\circ} 47^{\prime} 44^{\circ}$ "BT and $06^{\circ} 05^{\prime} 34^{\prime}$ LS. The date were analyzed by descriptive statistic. Results obtained both directly in the field and secondary date and then analyzed using descriptive statistical analysis. Air Blast Freezer at PTAWIndo International applies the operating system for 15 hours in 1 day with the temperature used is $-35^{\circ} \mathrm{C}$, this is done so that the quality of fish stored in the $\mathrm{ABF}$ is maintained quality until. Average raw material purchases during November 2016 totaled 118 with an average weight of $4,755 \mathrm{~kg}$ and average purchases during December 2016 were 123 with an average weight of 5,746.04kg. In December 2016 PT AWIndo International sells through 2 phases: Phase 1: Sales of 3 containers with 19 tons or $19,000 \mathrm{~kg}$ Phase 2: Sales of 1 container with 8 tons or $8,000 \mathrm{~kg}$ of processed tuna. Processed products are sold to Russia. In December 2016 PT AWIndo International sells through two phases: Phase 1: Sales of 4 containers with 25 tonnes or 25,000 KgTahap 2: Sales of 1 container with 11 ton or $11,000 \mathrm{~kg}$ of processed tuna, The products are sold to State.
\end{abstract}

Keywords: Handling of tuna, Air Blast Freezer, PT AWIndo International. 


\section{PENDAHULUAN}

\section{Latar Belakang}

Wilayah perairan laut Indonesia memiliki kandungan sumberdaya alam khususnya sumberdaya ikan yang berlimpah dan beraneka ragam.Berdasarkan data dari Sistem Informasi Diseminasi Data dan Statistik Kelautan dan Perikanan (SIDATIK), Produksi Perikanan Tangkap pada tahun 2016 sebanyak 6.351.480,00 ton.Dengan produksi ikan yang sebanyak ini diperlukan penanganan yang baik terhadap ikan hasil tangkapan terutama padacold storage.

Pelabuhan Perikanan Samudera Nizam Zachman Jakarta (PPSNZJ)merupakan Unit Pelaksanaan Teknis (UPT) Kementerian Kelautan dan Perikanan (KKP) yang berada dibawah dan bertanggung jawab kepada Direktorat Jenderal Perikanan Tangkap. PPSNZJ memiliki beberapa cold storage yang memiliki daya tampung dan penanganan yang baik terhadap ikan hasil tangkapan yang dimasukan ke dalam cold storage.

Salah satu perusahan dalam bidang pendinginan dan pembekuan ikan yang menggunakan $\mathrm{ABF}$ adalah PT AWIndo International yang berlokasi didalam kawasan PPSNZJ. ABF digunakan untuk pembekuan bahan baku ikan tuna yang akan dijadikan olahan pada PT AWIndo International yang nantinya akan diekspor ke beberapa negara tetangga.

Berlatar belakang kondisi tersebut maka penelitian dengan judul Penanganan Hasil Tangkapan Ikan Tuna Pada cold storage dengan Sistem Air Blast Freezer pada PT AWIndo International PPSNZJ.

\section{Perumusan Masalah}

Berdasarkan pendahuluan di atas, maka rumusan masalah dalam penelitian ini adalah sebagai berikut:

1) Bagaimana kondisi sistem air blast freezerpada cold storage di PT AWIndo International PPS Nizam Zachman Jakarta?

2) Bagaimana proses penanganan ikan tuna hasil tangkapan dengan sistem air blast freezer pada cold storage di PT AWIndo International PPS Nizam Zachman Jakarta?

\section{Tujuan Penelitian}

Berdasarkan rumusan masalah di atas, maka tujuan penelitian ini adalah:

1) Mengetahui kondisi sistem air blast freezerpada cold storagedi PT AWIndo International PPS Nizam Zachman Jakarta?

1) Mengetahui proses penanganan ikan tuna hasil tangkapan dengan sistem air blast freezer pada cold storage di PT AWIndo International PPS Nizam Zachman Jakarta?

\section{Manfaat Penelitian}

Manfaat dari penelitian ini adalah :

1) Memberikan tambahan pengalaman kepada peneliti mengenai penangan ikan yang baik di dalam cold storagedengan menggunakan sistem $\mathrm{ABF}$

2) Sebagai bahan informasi lanjutan bagi yang akan melakukan penelitian di perusahaan cold storage dengan menggunakan sistem $\mathrm{ABF}$. 


\section{METODOLOGI}

\section{Waktu dan Tempat}

Penelitian dengan judul "Penanganan Hasil Tangkapan Ikan Tuna di Cold Storage dengan Sistem Air Blast Freezer pada PT AWIndo International Pelabuhan Perikanan Samudera Nizam Zachman Jakarta", ini dilaksanakan di Pelabuhan Perikanan Samudera Nizam Zachman Jakarta, Jakarta Utara. PadaTanggal 1sampaidengan31Desember 2016.

\section{Alat dan Bahan}

Alat dan bahan yang digunakan dalam penelitian ini dapat dilihat pada Tabel2.

Tabel 2. Alat Penelitian

\begin{tabular}{|l|l|l|}
\hline No & \multicolumn{1}{|c|}{ Alat } & \multicolumn{1}{c|}{ Fungsi } \\
\hline 1 & Kamera & Untuk mendokumentasikan kegiatan penelitian \\
\hline 2 & Alat Tulis & Untuk mencatat hasil dari pengambilan data \\
\hline 3 & Laptop & Untuk pengetikan dan pengolahan data \\
\hline 4 & Timbangan & Untuk mengukur berat ikan \\
\hline 5 & Kuisioner & Mengumpulkan informasi dari pengelola cold storage \\
\hline
\end{tabular}

Bahan yang digunakan adalah ikan tuna hasil penangkapan yang dimasukan ke dalam cold storage dengan sistem $\mathrm{ABF}$.

\section{Metode Penelitian}

Metode yang digunakan pada kegiatan penelitian penangan hasil tangkapan ikan tuna pada cold storage dengan sistem ABF di PT AWIndo International PPS Nizam Zachman Jakarta adalah metode observasi dimana dilakukan pengambilan data dengan melakukan pengamatan secara langsung dan tanya jawab dengan petugas cold storage.

\section{Metode Pengumpulan Data}

Jenis data yang digunakan dalam penelitian ini adalah data primer dan data sekunder. Data primer diperoleh dari hasil wawancara langsung dengan responden yang terdiri dari manajer produksi dan pegawai cold storage. Data sekunder diperoleh dari data perusahaan, studi pustaka, literatur, penelitian terdahulu yang terkait serta media informasi internet.

\section{Analisa Data}

Data yang diperoleh kemudian dianalisis secara statistik deskriptif. Metode statistik deskriptif merupakan tipe analisis yang meliputi pengumpulan data, penyajian data, dan peringkasan data. Pembelianrata-rata bahan bakudihitungmenggunakan rumus:

Dimana :

$\Delta$ : Nilai Pembelian Rata-Rata

Q: Banyaknya Ikan yang Dibeli

n: Jumlah Pembelian Selama 1 Bulan

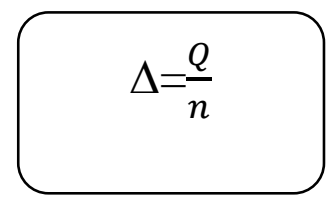




\section{KEADAAN UMUM DAERAH PENELITIAN}

\section{Lokasi Perusahaan}

PT Awindo International merupakan salah satu perusahaan yang bergerak di bidang pengolahan produk perikanan, termasuk salah satunya produk tuna loin.Perusahaan ini terletak di dalam kawasan PPSNZJ. Perusahaan ini berkomitmen pada produksi dan pemasaran serta terhadap keamanan produk perikanan dalam memenuhi persyaratan Internasional dan Indonesia pada sistem mutu Hazard Analysic Critical Control Point (HACCP) atau manajemen keamanan pangan.Adapun visi dan misi perusahaan tersebut.Visi perusahaan yaitu ingin memproduksi produk perikanan yang berkualitas ekspor dan sehat dikonsumsi manusia dan bisa menembus pasar Eropa, Amerika, Canada, Jepang, Korea Selatan dan Cina. Misi perusahaan yaitu akan menerapkan dan mengawasi panduan program Manajemen Mutu Terpadu berdasarkan konsepsi HACCP dengan baik dan benar untuk menjamin hasil olahan memenuhi standar yang ditetapkan.Sesuai dengan Keputusan Menteri Perhubungan Nomor KM.35/ AL.003/PHB-82 PPSNZJ tepatnya berlokasi pada koordinat : $106^{\circ} 48^{\prime} 15^{\prime \prime} \mathrm{BT}$ dan 0606'18'LS;

\section{Struktur Organisasi Perusahaan}

PT. AWIndo International dipimpin oleh seorang General Manager dengan tugas pokok mengambil keputusan operasional perusahaan, menetapkan kebijakan umum perusahaan, menentukan dan mengendalikan perusahaan, membina koordinasi yang baik dengan berbagai bidang kerja yang ada dibawahnya, meminta pertanggungjawaban dari masing-masing manager pelaksana (kepala bagian) serta bertanggung jawab atas kelangsungan hidup perusahaan. General Manager ini membawahi beberapa bagian yaitu bagian production staff, quality control, dan teknisi bagian mekanik, bagian pembelian bahan baku, bagian proses bagian acounting, bagian umum dan administrasi. Setiap kepala bagian ini bekerja sesuai dengan bidang atau bagiannya dengan penuh tanggung jawab dan saling berkoordinasi.

\section{Fasilitas Perusahaan}

PT AWIndo International memilikiberbagaimacamfasilitasdiantaranya:

1) Cold storage : 3 buah berkapasitas masing-masing 100 ton.

2) Air Blast Freezer: 6 Buah

3) Meja Kerja 40 buah

4) Keranjang 150 buah

5) Timbangan 20 buah

6) Kereta Dorong (Lori) 10 buah

7) Forklift

8) Kaporit

9) Listrik

10) Air

11) Fasilitas Limbah 


\section{HASIL DAN PEMBAHASAN}

\section{Proses Penyimpanan Ikan pada ABF}

\section{Penyimpanan dengan Suhu RendahPada ABF}

PT AWIndo International menggunakan Air Blast Freezer $(A B F)$ untuk sistem penyimpanan dengan suhu rendah. Hal ini dilakukan agar kualitas ikan yang akan diekspor tetap terjaga kualitasnya, suhu yang digunakan pada ABF PT. AWIndo International adalah $-35^{\circ} \mathrm{C}$.

Lama waktu pengoperasian pada ABF PT AWIndo International adalah 8 jam dalam 1 hari, ABF pada PT AWIndo International menerapkan suhu rendah hingga $35^{\circ} \mathrm{C}$ agar struktur daging ikan tuna yang disimpan didalamnya tidak mengalami kerusakan hingga dikirim ke negara-negara pemesan. PT AWIndo International memiliki 6 ruang ABFfreezer dengan kapasitas masing-masing 4 ruang sebesar 2,5 tondan 2 ruangberkapasitas 5 ton. Ruang ABF freezer tersebut dilengkapi dengan alat pengatur dan monitor suhu yang terdapat di bagian luar ruang ABFfreezer sehingga dapat dilihat dengan mudah. Monitoring suhu ABF dilakukan setiap jam oleh operator.

\section{Jenis Produk yang dihasilkan PT AWIndo International}

Produk olahan yang dihasilkan PT AWIndo International diantaranya tuna saku, tuna steak, tuna chunk, tuna loin center cut, dan tuna cube. Perusahaan ini melakukan ekspor olahan tuna ke negara Jepang, Korea, Amerika dan Rusia

\section{Proses Penanganan Ikan di dalamCold Storage denganSistem ABF}

Proses penanganan dan pembuatan produk tuna di PT AWIndo International Jakarta terdiri dari beberapa tahap. Proses penanganan ini dilakukan dengan teliti dan baik, hal ini dilakukan agar mendapatkan hasil olahan yang maksimal. Produk yang dihasilkan merupakan produk tuna beku jadi yang sudah siap untuk dijual.

PT AWIndo International Jakarta menerapkan keamanan yang ketat dalam proses produksi tuna beku ini. Langkah ini dilakukan dengan tujuan agar produk yang dihasilkan bisa aman untuk dikonsumsi. Tahap produksi ini selalu diawasi oleh petugas quality control yang bertugas memastikan bahwa produk yang dihasilkan memiliki mutu yang baik, higienis, dan tidak ada kerusakan. Tahap-tahap proses penanganan hingga pembuatan produk tuna secara rinci yang dilakukan di PT AWIndo International Jakarta adalah sebagai berikut : 


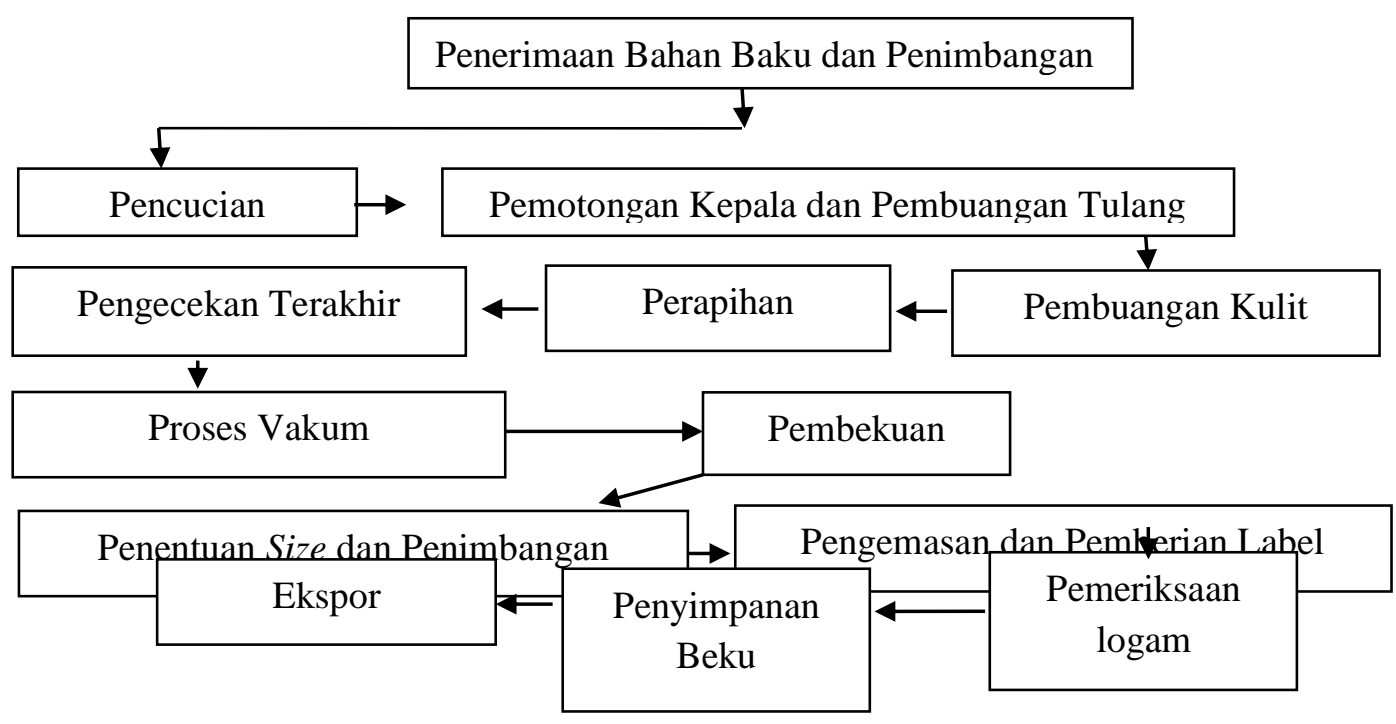




\section{PembagianGradepadaOlahanIkan Tuna}

PT AWIndo International menggunakan bahan baku tuna dengan grade yang berbeda. Grade yang digunakan oleh perusahaan ini adalah bahan baku tuna yang memiliki grade $\mathrm{B}, \mathrm{C}$, dan $\mathrm{D}$. Ciri-ciri untuk masing-masing grade tuna segar diacupada (Fadly, 2009).

\section{Ketenagakerjaan}

PT AWIndo International memiliki karyawan sebanyak 76 orang, yang tersebar kedalam beberapa tingkatan. Pembagian kerja menurut keahlian yang dimiliki tenaga kerja tersebut. Sehingga pembagian kerja ini tidak bertolak belakang dengan tujuan dari perusahaan ini. Sebanyak 20 orang karyawan dipekerjakan khusus untuk produksi pengolahan tuna beku. Sisanya tersebar di beberapa bagian, diantaranya staf mekanik, staf pembelian, staf accounting, dan staff umum.

\section{Ketersediaan Bahan Baku dan Sumber Bahan Baku}

Bahan baku produksi PT AWIndo International diperoleh dari transheed 17 pembelian yang ada di Muara Baru. Tuna yang diterima di PT AWIndo International ada dua jenis, yaitu yellow fin tuna dan big eye tuna. Pemenuhan kebutuhan bahan baku dilakukan oleh PT AWIndo International melalui pembelian ke pemilik kapal maupun ke transheed yang ada di Muara Baru.

\section{Pembelian Bahan Baku Bulan November 2016}

Pembelian bahan baku tuna pada PT AWIndo International bulan November 2016 tidak dilakukan setiap hari, pembelian dilakukan yakni sekitar 2 hari sekali disesuaikan dengan permintaan dari konsumen, pembelian bahan baku pada bulan November 2016 adalah 2.498 ekor dengan berat $95.100 \mathrm{Kg}$, tingkat pembelian ratarata selamabulan November adalah 118 ekordanberat rata-rata adalah4.755 Kg

\section{Pembelian Bahan Baku Bulan Desember 2016}

Pembelian bahan baku tuna pada PT AWIndo International bulan desember 2016 adalah 2.589 ekor dengan berat $120.667 \mathrm{Kg}$, tingkat pembelian rata-rata bulan Desembe radalah 123 ekor dan berat rata-rata adalah5.746.04 Kg

\section{Penjualan ProdukHasilOlahan}

Pada bulan November 2016 PT AWIndo International melakukan penjualan melalui 2 tahap:

Tahap 1: Penjualan 3container dengan jumlah 19 ton atau sebanyak $19.000 \mathrm{Kg}$ hasil olahan ikan tuna. Ikan-ikan ini dijual ke Benua Eropa yang dimana Negara yang lebih banyak memesan adalah Rusia.

Tahap 2: Penjualan 1 container dengan jumlah 8 ton atau sebanyak $8.000 \mathrm{Kg}$ hasil olahan ikan tuna. Hasil olahan tersebut di ekspor dan dijual ke negara pemesan salah satunya Rusia. Rusia merupakan satu-satunya Negara di Eropa yang menjadi tujuan ekspor ikan olahan Tuna dari PTA WIndo International yang berada di Indonesia tepatnya di PPSNZJ Muara Baru pada bulan Desember 2016.

Pada bulan Desember 2016 PT AWIndo International juga melakukan penjualan melalui 2 tahap: 
Tahap 1: Penjualan 4 container dengan jumlah 25 ton atau sebanyak $25.000 \mathrm{Kg}$ hasil olahan ikan tuna.Ikan-ikan ini dijual ke Benua Eropa yang dimana Negara yang lebih banyak memesan adalah Rusia.

Tahap 2: Penjualan 1 container dengan jumlah 11 ton atau sebanyak $11.000 \mathrm{Kg}$ hasil olahan ikan tuna.Hasil olahan tersebut diekspor dan dijual ke negara pemesan salah satunya adalah Rusia. Rusia merupakan satu-satunya Negara di Eropa yang menjadi tujuan ekspor ikan olahan Tuna dari PTAWIndo International yang berada di Indonesia tepatnya di PPSNZJ Muara Baru pada bulan Desember 2016.

\section{Limbah Produk Hasil Olahan}

PTAWIndo International memiliki limbah produk hasil olahan terdiri dari kepala, tulang, dasi, sirip dan ekor, limbah sisa hasil olahan ini tidak dibuang tetapi dimanfaatkan untuk pakan ternak (bebek, itik, danangsa). Limbah-limbah ini dijual ke peternak yang datang dari Pulau Jawa (Jawa Timur dan Jawa Tengah), limbah-limbah ini dibeli dengan harga Rp. 6.000,-/Kg untuk tulang yang masih ada dagingnya dan Rp. $600,-/ \mathrm{Kg}$ untuk sirip, kepala dan ekor yang tidak memiliki daging. Para pembeli datang ke PT AWIndo dalam waktu sekali dalam seminggu.

\section{KESIMPULAN DAN SARAN}

\section{Kesimpulan}

Berdasarkan hasil penelitian penanganan ikan hasil tangkapan pada ABF di PT AWIndo International tersebut maka kesimpulan yang penulis kemukakan yaitu:

1) PT AWIndo International memiliki 6 buah $\mathrm{ABF}$ dengan 4 buah freezer berkapasitas 2,5 ton dan 2 buah freeze rberkapasitas 5 ton.

2) $\mathrm{ABF}$ pada PT AWIndo International menerapkan sistem $\mathrm{ABF}$ freezer beroperasi 8 jam dalam 1 hari dengan suhu yang digunakan $-35^{\circ} \mathrm{C}$, ini dilakukan agar mutu ikan yang disimpan dalam ABF tetap terjaga hingga dikirim ke Negara-Negara pemesan.Proses penanganan dilakukan mulai dari penerimaan bahan baku dan penimbangan, pencucian, pemotongan kepala, pembuangan tulang, pembuangan kulit, perapihan, pemotongan (merubah bahan baku sesuai pesanan, pengecekan terakhir, proses vakum, pembekuan, penentuan size dan penimbangan, pemeriksaan logam, pengemasan dan pemberian label, penyimpanan beku, dan ekspor.PT AWIndo International menggunakan bahan baku tuna dengan grade $\mathrm{B}, \mathrm{C}$ dan grade $\mathrm{D}$. Pembelian bahan baku rata-rata selama bulan November 2016 adalah 118 ekor dengan berat $4.755 \mathrm{Kg}$ dan pembelian rata-rata selama bulan Desember 2016 adalah 123 ekor dengan berat rata-rata adalah $5.746 .04 \mathrm{Kg}$.

\section{Saran}

Berdasarkan penelitian yang dilakukan maka saran dari penelitian ini adalah:

1) Untuk menjaga tetap stabilnya persedian bahan baku di perusahaan, maka pihak perusahaan perlu melakukan perencanaan pembelian bahan baku yang baik. Sehingga bahan bakuselalu tersedia di perusahaan.

2) Perlu dilakukan penelitian lanjutan mengenai bagaimana strategi terbaik untuk menyelesaikan permasalahan-permasalahan yang ada di sepanjang rantai pasok. 


\section{DAFTAR PUSTAKA}

Fadly, N. 2009. Asesmen Resiko Histamin Ikan Tuna (Thunnus sp.) Segar Berbagai Mutu Ekspor Pada Proses Pembongkaran (Transit) Skripsi. Institut Pertanian Bogor, Bogor.

http://www.awindointernational.com/abautus.php [diakses tanggal19 Oktober 2016].

http://statistik.kkp.go.id/sidatik-dev/2.php?x=2 [diakses tanggal 20 Juni2017]. 